\title{
O Instituto de Coimbra e o Ensino Secundário em Portugal na Primeira República. $O$ caso particular das Ciências Físico-Químicas
}

\author{
António J. Leonardo, Décio R. Martins \& Carlos Fiolhais \\ Universidade de Coimbra, Portugal
}

\begin{abstract}
Resumo
Analisamos o ensino secundário em Portugal após a reforma de 1905 e durante a Primeira República tendo por base a revista $O$ Instituto, publicada pela sociedade científica e literária Instituto de Coimbra (IC), com ênfase no estudo das Ciências Físico-Químicas. Discutimos algumas memórias de sócios do IC, como Bernardino Machado, Adolfo Coelho e Costa Lobo, que intervieram nas reformas realizadas. Destacamos as relações entre Portugal e Espanha no domínio da educação, em particular o artigo de Rubén Landa, um professor espanhol que foi em 1918 comissionado para estudar o ensino secundário em Portugal. Esta visita surgiu na sequência de um outro estudo solicitado pelo governo espanhol sobre a instrução pública no nosso país, realizado em 1914 pela portuguesa Alice Pestana, professora na Institución Libré de Enseñanza (ILE), em Madrid. Os dois estudos louvaram o ensino secundário português. No entanto, esse ensino era apenas para um número escasso de alunos.
\end{abstract}

Palavras-chave

Ensino secundário; Instituto de Coimbra; ILE; Primeira República

\section{Introdução}

A implantação em Portugal do regime republicano, em 5 de outubro de 1910, desencadeou um conjunto vasto de reformas no ensino público. O afã 
reformista não foi, porém, muito lesto na organização do ensino secundário, tendo decorrido alguns anos até ocorrer uma mudança profunda neste nível de ensino. Tal poderá ser atribuído à forte influência que várias personalidades republicanas tinham exercido na última reforma da monarquia constitucional, que tinha tido lugar em 1905.

Um dos mais importantes veículos usados para divulgar pontos de vista sobre assuntos educativos foi $O$ Instituto, revista literária e científica publicada pela sociedade académica coimbrã com o mesmo nome. O Instituto de Coimbra (IC), fundado em 1852, congregou não só um vasto leque de académicos nacionais, a maior parte professores da Universidade de Coimbra (UC), mas também alguns académicos estrangeiros, numa atividade desenvolvida ao longo de quase século e meio (Leonardo, Martins \& Fiolhais, 2009a; Saraiva, 1993). O Instituto, com 141 volumes publicados desde 1852 até 1981 , foi o produto mais visível do labor desta academia ${ }^{1}$.

Muitos artigos publicados nessa revista tiveram como tema o ensino público, sobressaindo o ensino secundário. A relevância que têm para a história da educação é comprovada pela inclusão de $O$ Instituto no Repertório Analítico da Imprensa de Educação e Ensino (Nóvoa, 1993a, pp. 527-533). Nóvoa considera quatro momentos respeitantes à publicação de artigos relativos ao ensino n'O Instituto, a saber: até 1860, onde surgem os relatórios e conferências do Conselho Superior de Instrução Pública (CSIP) e vários artigos sob a epígrafe de Instrução Pública; entre 1860 e 1880, um período de acentuado decréscimo no tratamento desse tipo de questões devido à ausência do CSIP; entre 1880 e 1930, que pode ser considerado um "período áureo" da atenção aos problemas educativos, não tanto pela quantidade mas mais pela qualidade dos artigos publicados (ver Tabela 1); e, finalmente, a partir de 1930, quando diminuiu bastante o número de artigos sobre o tema².

Noutro artigo, analisámos o ensino na monarquia constitucional visto pel'O Instituto (Leonardo, Martins \& Fiolhais, 2009b). Neste, com base no corpus de artigos sobre o ensino publicados na referida revista durante a Primeira República, assim como no período imediatamente anterior, descreveremos as principais reformas efetuadas na educação em Portugal, os fatores que terão condicionado as decisões políticas neste quadro e as propostas que foram sendo discutidas, ao mesmo tempo que aferimos o grau de desenvolvimento deste nível de ensino na opinião de membros do IC que foram protagonistas das políticas de educação nacional e também de alguns 
analistas externos, como foi o caso da portuguesa, residente em Espanha, Alice Pestana e do espanhol Rubén Landa. Daremos, na nossa análise, uma atenção particular à evolução do ensino das Ciências Físico-Químicas, como um bom exemplo da atenção que nessa altura começou a ser dada ao ensino experimental das ciências.

\section{Tabela 1}

\begin{tabular}{|c|c|c|c|c|}
\hline \multicolumn{5}{|c|}{$\begin{array}{l}\text { Artigos no âmbito do Ensino Secundário e da Pedagogia } \\
\text { publicados n'O Instituto entre } 1880 \text { e } 1930\end{array}$} \\
\hline Autor & Ano & Título & Vol. & Páginas \\
\hline Bernardino Machado & 1882 & O estado da instrucção secundaria entre nós & 30 & $206-215$ \\
\hline Albino Coelho & 1884 & Reforma dos methodos de ensino & 31 & $391-400,577-582$ \\
\hline F. Teixeira Bastos & 1893 & $\begin{array}{l}\text { Ideias geraes sobre a evolução da pedagogia } \\
\text { em Portugal }\end{array}$ & 40 & $489-513$ \\
\hline $\begin{array}{l}\text { Francisco Giner del } \\
\text { Rios }\end{array}$ & 1896 & $\begin{array}{l}\text { Las vacaciones en los establecimientos de } \\
\text { enseñanza }\end{array}$ & 43 & $506-515$ \\
\hline Bernardino Machado & 1896 & A reforma de instrucção secundaria (excerpto) & 43 & $752-761$ \\
\hline Bernardino Machado & 1896 & A educação nova em Hespanha & 43 & $494-497$ \\
\hline Bernardino Machado & 1896 & $\begin{array}{l}\text { Congresso pedagogico hispano-português- } \\
\text { americano e exposição pedagogica } \\
\text { portuguêsa em Madrid }\end{array}$ & 43 & $498-505$ \\
\hline Bernardino Machado & 1900 & Curso de pedagogia & 47 & $80-84,130-148,193-197$ \\
\hline F. Adolpho Coelho & 1901 & A distribuição do ensino e a selecção social & 48 & $\begin{array}{l}153-167,265-277,348-353 \\
489-507\end{array}$ \\
\hline F. Adolpho Coelho & 1902 & $\begin{array}{l}\text { As despesas do ensino em Portugal no fim do } \\
\text { seculo XIX }\end{array}$ & 49 & $449-463$ \\
\hline $\begin{array}{l}\text { António José } \\
\text { Gonçalves Guimarães }\end{array}$ & 1902 & Reforma do ensino secundário & 49 & $513-533$ \\
\hline Bernardino Machado & 1902 & O actual regimen do ensino secundario & 49 & $641-660$ \\
\hline Daniel Rodríguez & 1909 & O ensino da Grammatica nas linguas vivas & 56 & $209-218$ \\
\hline $\begin{array}{l}\text { Jorge da Rocha } \\
\text { Peixoto }\end{array}$ & 1910 & $\begin{array}{l}\text { O ensino das linguas vivas na educação } \\
\text { moderna }\end{array}$ & 57 & $\begin{array}{c}337-343,401-411,462-472 \\
520-535\end{array}$ \\
\hline F. Adolpho Coelho & 1911 & Questões pedagogicas & 58 & $\begin{array}{c}23-36,71-78,129-137,193- \\
202,257-268,385-395,577- \\
587,641-647,705-711\end{array}$ \\
\hline F. Adolfo Coelho & 1913 & Programas e planos de ensino & 60 & $401-411$ \\
\hline F. M. da Costa Lobo & 1919 & $\begin{array}{l}\text { Educação Pública: Reforma da Instrução } \\
\text { Secundária }\end{array}$ & 66 & $179-198$ \\
\hline $\begin{array}{l}\text { José del Prado y } \\
\text { Palacio }\end{array}$ & 1919 & $\begin{array}{l}\text { Reforma da Instrução Pública em Espanha: } \\
\text { Discurso proferido na sessão de } \\
\text { encerramento, pelo Sr. D. José del Prado y } \\
\text { Palacio, Ministro da Instrução Pública }\end{array}$ & 66 & $517-536$ \\
\hline João da Silva Correia & 1924 & $\begin{array}{l}\text { Educação do pensar imaginativo e do pensar } \\
\text { lógico }\end{array}$ & 71 & $262-275$ \\
\hline Rubén Landa & 1927 & La enseñanza secundaria en Portugal & $\begin{array}{l}74 \\
75 \\
76\end{array}$ & $\begin{array}{l}44-85,204-225,202-217 \\
437-454,63-75\end{array}$ \\
\hline F. M. da Costa Lobo & 1935 & A educação e o problema económico & 88 & $408-455$ \\
\hline
\end{tabular}




\section{A pedagogia das ciências em Portugal no início do século $\mathbf{X X}$}

No último quartel do século XIX surgiram em Portugal várias ideias pedagógicas, algumas delas arrojadas para a época. Os ideais republicanos repercutiam-se na área educativa, tendo sido propostas várias reformas no modo de ensinar todas as disciplinas, mas mais em particular as disciplinas científicas. Durante a monarquia, personalidades associadas às ideias e ao movimento republicano, como Teófilo Braga, Francisco José Teixeira Bastos ${ }^{3}$, José Augusto Coelho, etc., foram destacados proponentes da chamada pedagogia positivista, que considerava o método científico o verdadeiro meio de alcançar a verdade (Proença, 2002, pp. 42-43). No ideário republicano, a ciência vinha, de certo modo, ocupar o lugar que antes era ocupado pela religião, não admirando por isso que propugnasse o total laicismo do Estado. Por outro lado, o ensino deveria ter por função a educação para a cidadania, defendendo-se a liberdade do homem e a necessidade da instrução pública para o progresso da sociedade (Catroga, 2000, pp. 131-134; Fernandes, 1979).

Neste quadro, são de destacar as ideias de Bernardino Luís Machado Guimarães (1851-1944), professor de Antropologia na Universidade de Coimbra e por duas vezes Presidente da República. Tendo desempenhado as funções de presidente do IC entre 1896 e 1908, Bernardino Machado privilegiou $O$ Instituto na publicação dos seus artigos. Alguns deles incidiram sobre o ensino e a pedagogia, revelando neles as suas ideias que se dirigiam principalmente ao ensino das ciências (Leonardo et al., 2009b; e, em especial, Leonardo, Martins \& Fiolhais, 2011). Argumentou que o ensino secundário deveria possuir uma "ampla base cultural, sem cunho profissional mas voltado para a realidade" (Fernandes, 1978, pp. 120-121). Opôs-se vigorosamente ao ensino abstrato e formal, em favor de um ensino moderno "firmado numa coerente lógica curricular, hierarquizada segundo as conceções científicas do tempo e tendo na realidade viva os seus fulcros de aplicação" (idem). Queria que os liceus fossem escolas ativas, escolas em que os alunos participassem no processo educativo, considerando que estes "não têm amor nenhum a soluções científicas que não Ihes custaram esforço, e defendem-nas como bonitas frases" (Fernandes, 1985, p. 123). Achava essencial a substituição do estilo psitacístico, no qual se repetiam as frases dos mestres, por uma reelaboração crítica e consciente dos conteúdos cognitivos através da 
valorização pedagógica do aluno como sujeito da aprendizagem (idem, p. 152). Contudo, não propôs práticas baseadas nas tendências tecnocratizantes da pedagogia, reduzindo o ensino a aspetos tecnodidácticos, preferindo antes realçar a relação entre o ensino e a prática e os laços entre professor e aluno, sempre numa perspetiva humanista da educação. $\mathrm{O}$ professor tinha a obrigação de exemplificar o respeito que votava à ciência, devendo inspirar esse mesmo respeito no aluno. A exposição do professor, combinada com a ilustração dos objetos e instrumentos, mas, sobretudo, com a própria realidade das coisas experimentadas ou observadas, teria de atrair os educandos e fazê-los "inventar para si a [ciência] que os outros já possuem" (idem). A proximidade com as ideias construtivistas é evidente neste trecho.

Em 1900, Bernardino Machado apresentou cinco lições no IC, que intitulou Curso de Pedagogia, ao longo das quais dissertou sobre esse tema. A primeira dessas lições, publicadas n'O Instituto, incidia sobre a importância do ensino e da formação pedagógica dos candidatos ao magistério liceal. Nas seguintes discorreu sobre algumas ideias pedagógicas avulsas, invocando por exemplo a necessidade de ter professores que, para além de bem preparados no plano científico, se destacassem no plano moral, sendo radicalmente intransigentes com a corrupção ou outro mal (Machado, 1900, p. 132).

As ideias pedagógicas defendidas por Bernardino Machado haveriam de se refletir nos programas de Física e de Química de 1905 e no surgimento da disciplina de "Trabalhos práticos" em 1914

\section{A Revolução Republicana e as suas implicações no Ensino Secundário}

A 2 de novembro de 1910, não tinha ainda decorrido um mês após a revolução republicana, já o ministro do Interior do Governo provisório tinha nomeado uma comissão de nove membros ${ }^{4}$ para formular um novo plano geral de reorganização dos estudos portugueses. Embora o objetivo fosse executar os princípios pedagógicos que serviram de propaganda política na última fase da monarquia (Proença, 2002, p. 44), as condições socioeconómicas do país condicionaram o cumprimento deste desiderato. 
No caso do ensino secundário, os ânimos dos políticos e pedagogos encontravam-se apaziguados desde a reforma de 19055. Com efeito, o diploma que a instituiu gerou um largo consenso entre os pedagogos republicanos (Brás \& Gonçalves, 2009, p. 108), uma vez que atendeu a muitas das pretensões que eles defendiam, designadamente a introdução da educação física e o maior relevo dado ao ensino das ciências e das línguas vivas, modernizando o ensino e reforçando o seu caráter utilitário.

A reforma de 1905, da autoria de Eduardo José Coelho (1835-1913), traduziu-se num conjunto de ajustes à reforma de 1884/85, elaborada por Jaime Moniz com o apoio de Adolfo Coelho, ambos professores do Curso Superior de Letras de Lisboa, sendo João Franco ministro do reino. Justificouse, entre outros motivos, pelo peso exagerado do ensino clássico da reforma original de Jaime Moniz, na qual a disciplina de Latim era a que tinha maior carga horária ${ }^{6}$, prolongando-se pelos sete anos do curso completo, mas também como resposta à "campanha de protesto popular" a que esta última vinha sendo sujeita (Valente, 1973, p. 73). Não tendo por base uma nova orientação pedagógica, a reforma de Coelho procurou corrigir alguns defeitos da anterior. Desta maneira, foi retirado o Latim dos primeiros três anos e bifurcou-se o ensino nos últimos dois anos nos cursos complementares de Letras e Ciências. Foi também aumentada a carga horária das disciplinas científicas no curso geral (Ciências Físicas e Naturais), surgindo a Física, a Química e as Ciências Naturais como disciplinas independentes no curso complementar de Ciências. As chamadas línguas vivas (Inglês, Francês ou Alemão) adquiriram maior peso horário. Assim, esta reforma constituiu um verdadeiro progresso no sentido de tornar o ensino secundário um meio de preparação para a vida ativa e não, como acontecia antes, um mero patamar intermédio entre a escola primária e a escola superior. Tal situação, em que a escola surgia "como um novo saber e poder", teve alguma longevidade (Brás \& Gonçalves, 2009, p. 116).

Os programas de Física e Química, integrados na disciplina de Ciências Física e Naturais do curso geral, parecem decalcados de muitas das ideias pedagógicas de Bernardino Machado, em particular o facto de 0 programa de Física se assumir como meramente "indicativo e não taxativo", ficando ao "prudente arbítrio do professor a fixação dos methodos e processos que sejam precisos" (Decreto de 3 de novembro de 1905). O 
programa considerava que as demonstrações experimentais eram o único fim do curso, devendo a disciplina ter um caráter prático e experimental, e devendo os conteúdos de Física ser intuitivos e descritivos.

Em 1911, Francisco Adolfo Coelho (1847-1919) iniciou a publicação n'O Instituto de um artigo, em várias partes, intitulado Questões Pedagógicas. Adolfo Coelho foi um erudito filólogo, professor do Curso Superior de Letras em Lisboa (Fernandes, 1973) e sócio correspondente do IC, que já tinha intervindo na reforma protagonizada por Jaime Moniz de 1894-95: foram da sua autoria os programas das disciplinas de Geografia, Francês e Inglês (Leonardo et al., 2009b). Foi, também, um reconhecido pedagogo, tendo lecionado a cadeira de Pedagogia do Ensino Secundário, criada no Curso Superior de Letras de Lisboa (Coelho, 1911, p. 134). Numa parte do seu artigo, intitulada $O$ plano geral do ensino público, Coelho renovou uma proposta que já tinha apresentado na Sociedade de Geografia, 18 anos antes, no sentido de realizar um "congresso nacional para a discussão e o estudo da situação da ciência portuguesa nos seus diversos ramos, aplicações, necessidades e progressos, congresso em que as questões de ensino teriam lugar predominante" (Coelho, 1911, p. 72). Considerando que "as reformas educativas são das mais difíceis de realizar", reiterou as Bases Gerais de uma Reforma do Ensino Público Português, que tinha publicado sob a forma de opúsculo sob os auspícios da Sociedade de Geografia em 1894. Deste projeto destacamos dois aspetos em relação ao ensino secundário: a divisão da instrução em clássica (que incluía o estudo das línguas clássicas) e moderna (que excluía esse estudo); e a disposição dos programas não por disciplinas, mas por partes relacionadas entre si, fazendo suceder os conhecimentos numa ordem adequada ao desenvolvimento psicológico dos alunos. A ambos os cursos, moderno e clássico, seriam comuns cadeiras de índole científiconatural (Geografia, Física, Elementos de Química, História Natural e Matemática) (idem, pp. 131-133). Adolfo Coelho presidiu à nova comissão, nomeada em 26 de junho de 1911, encarregada de organizar um projeto de reforma deste grau de ensino ${ }^{7}$. No relatório elaborado por esta comissão ficaram plasmadas as ideias de Adolfo Coelho, designadamente a existência de dois cursos no ensino secundário, servindo o clássico, que incluía o Latim e o Grego, de preparação aos cursos superiores das Faculdades de Letras e Direito, e o moderno, com as ciências e as línguas vivas, direcionava os 
alunos para as Faculdades de Ciências, Medicina e escolas e institutos técnicos ${ }^{8}$ (Carvalho, 1986, pp. 683; Fernandes, 1973, pp. 435-442). Estes trabalhos não foram aproveitados, ficando por aplicar estas medidas, provavelmente por restrições de ordem financeira e contenção dos governos perante uma reforma radical, que atribuía ao curso liceal oito anos de duração.

Com vista à formação de professores para os ensinos primários e liceal, foram, por decreto de 21 de maio de 1911, criadas Escolas Normais Superiores, anexas às Universidades de Coimbra e Lisboa (esta última acabada de criar), que deveriam desempenhar um papel relevante na transformação pretendida ${ }^{9}$. $\mathrm{O}$ acesso a estas escolas exigia $\circ$ grau de licenciado ou bacharel, podendo os candidatos optar pelos cursos de habilitação para os magistérios liceal, normal primário e primário superior. Cada curso tinha a duração de dois anos, sendo o primeiro dedicado à preparação pedagógica e o segundo à iniciação à prática pedagógica. $\mathrm{A}$ habilitação para o ensino das ciências incluía uma disciplina sobre a metodologia geral das Ciências Matemáticas e das Ciências da Natureza (Valente, 1973, pp. 129-132).

Em 1913, Adolfo Coelho voltou a publicar um artigo n'O Instituto, onde analisou os programas e planos do ensino secundário de várias nações. Neste ensaio, centrou-se no perfil do professor, considerando que havia muitos professores "lentos, pachorrentos, soporíferos, gastando muito tempo e moendo o seu programa" (Coelho, 1913, p. 403). Sobre a metodologia a adotar na lecionação dos novos programas, baseada nos sistemas vigentes em países europeus como a Alemanha, salientou as contradições que estes revelavam apesar de serem evidentes traços comuns, designadamente as novas regras pedagógicas, que mandavam avançar do fácil para o difícil, do simples para o composto e do próximo para o remoto (idem). Acentuou a necessidade de só se apresentar aos educandos aquilo que estes estivessem preparados para entender e de thes dar liberdade de escolha entre algumas disciplinas de opção nas classes superiores do ensino secundário. Finalmente, refletiu sobre as diferenças de "inteligência" dos alunos, defendendo a divisão entre os melhores e os "medíocres", devendo a estes ser proporcionado um ensino mais geral. 
Em 26 de setembro de 1914, num governo liderado por Bernardino Machado, foram aprovados os "trabalhos práticos individuais" no curso complementar do secundário, que previam a realização autónoma por parte dos alunos de problemas de investigação, sob a direção de um ou mais professores ${ }^{10}$. Esta medida pretendeu pôr em prática um ensino mais ativo, levando o aluno a desenvolver as suas "faculdades de investigação e habituálo à prática dum método de estudo e de trabalho" (Decreto 896 de 26 de setembro de 1914). As instruções determinavam que estes trabalhos não deveriam "ter a feição de mera execução de receitas", devendo o professor comportar-se como "companheiro de trabalho" (Portaria 239 de 26 de setembro de 1914).

Só em 1917 foi reformulado o ensino secundário com base na proposta da comissão nomeada para esse fim. $O$ decreto $n .^{\circ} 3091$, de 17 de abril, regulamentou o ensino secundário inspirado na experiência do Liceu Pedro Nunes de Lisboa (Landa, 1927, p. 215). No essencial mantiveram-se as disposições da legislação anterior, sendo introduzidas as Ciências Físicas e Naturais no curso complementar de Letras e a Filosofia no curso complementar de Ciências. Verifica-se que as maiores alterações incidiram na regulamentação administrativa dos liceus. As críticas de que este decreto foi alvo por parte dos estudantes conduziram à suspensão das aulas liceais durante alguns meses. A contestação prendia-se com a alegada sobrecarga dos programas dos cursos complementares, que penalizavam fortemente os alunos. Em virtude da fragilidade política do governo, este optou por revogar este projeto, tentando amenizar o novo foco de descontentamento na sociedade (Landa, 1927, pp. 215-216; Valente, 1973, pp. 83-84).

Em dezembro de 1917 ocorreu a revolta que colocou no poder Sidónio Pais (1872-1918), professor de Matemática de Coimbra que acumulou o cargo de Presidente da República com a chefia do governo e as pastas da Guerra e dos Negócios Estrangeiros. Outro professor de Matemática de Coimbra, amigo de Sidónio Pais, Francisco de Miranda de Costa Lobo (1864-1945), então presidente do IC, foi então nomeado presidente da Comissão da Reforma de Ensino. A 14 de julho de 1918 foi aprovado o decreto que reformou a instrução secundária, tendo a 8 de setembro desse mesmo ano sido ratificado o novo regulamento. Manteve-se a duração do curso geral em cinco anos, surgindo a disciplina de Ciências Físico-Químicas, separada das 
Ciências Naturais, no $3^{\circ}$ ano (2. ${ }^{a}$ secção). Conservaram-se também os cursos complementares de Letras e Ciências, com a duração de dois anos, aparecendo no curso de Letras uma disciplina de Ciências Físico-Naturais e no curso de Ciências a cadeira de Matemática e, em separado, as de Física, de Química e de Ciências Naturais. Ambos os cursos tinham em comum as disciplinas de Português e Literatura Portuguesa, Inglês ou Alemão, e Geografia. Segundo a nova lei, o curso complementar de Ciências só poderia ser ministrado em liceus com gabinetes e laboratórios equipados com material para os trabalhos práticos individuais de Química, Física, Mineralogia, Geologia, Ciências Biológicas e Geografia.

Cerca de duas semanas antes do assassinato de Sidónio Pais, o decreto $n{ }^{\circ} 5002$, de 27 de novembro de 1918, aprovou os novos programas do ensino secundário. Nos programas de Física e de Química foram retiradas muitas das instruções constantes nos programas de 1905. Contudo, mantevese a intenção de fornecer aos alunos o conhecimento acerca dos principais fenómenos de Física, que deveriam ser induzidos da observação e experimentação. Por seu lado, a Química deveria versar as propriedades diretamente observáveis, postas em evidência através de experiências simples (Decreto n. ${ }^{\circ} 5002$ de 27 de novembro de 1918). Mantiveram-se os trabalhos práticos, com a mesma orgânica, que se estenderam a todos os liceus com o curso complementar de Ciências.

Após o assassinato do Presidente Sidónio Pais, Costa Lobo abandonou a política ativa. Contudo, no ano seguinte, publicou n'O Instituto um artigo sobre a reforma da instrução secundária apresentando um plano radicalmente diverso do aprovado em 1918 (Lobo, 1919). Para começar, Costa Lobo entendia a instrução secundária não como um fim em si mesma, mas como uma passagem para estudos superiores ou para estudos técnicos. A educação geral secundária deveria dividir-se em dois graus, o primeiro, de três anos, para alunos entre os 11 e os 14 anos, e o segundo, de dois anos, para alunos dos 14 aos 16 anos, em paralelo com uma Educação Especial: agrícola e de artes e ofícios (alunos dos 9-14 anos) e escolas agrícolas, industriais e comerciais (alunos dos 11 aos 15 anos). Ao nível da avaliação, classificou os exames como um "espetáculo inútil para escangalhar os organismos", defendendo antes provas sucessivas durante o ano, tornandose a prova final uma "formalidade sem surpresa (...) e de rápida execução" 
(idem, p. 184). Como forma de reduzir o número excessivo de horas, Costa Lobo propôs o limite de três cadeiras anuais, estabelecendo no $3 .^{\circ}$ ano $\left(3 .^{\text {a }}\right.$ classe) as disciplinas de Elementos de Física e Química, Botânica e Zoologia, Mineralogia e Geologia, e no $3 .^{\circ}$ ano $\left(4 .^{a}\right.$ classe) a cadeira de Física e Química. O ensino das ciências deveria ser feito "à vista de exemplares ou aparelhos", devendo partir-se das experiências ou exercícios precisos para a sua compreensão (idem, p. 187). Aconselhou o uso, nas aulas, de projeções. Os professores deveriam ser agrupados por secções (secção 5 . $^{\mathrm{a}}$ - Ciências Físico-Químicas e História Natural), devendo ser concedida, a cada secção, uma viagem ao exterior de seis meses.

\section{As relações entre Portugal e Espanha}

É digno de realce o intercâmbio pedagógico que se realizou nessa altura entre Portugal e Espanha, em particular porque vai permitir o estudo do ensino secundário realizado em Portugal por Rubén Landa.

O interesse da Espanha pela evolução do sistema educativo português foi confirmado pela deliberação do então ministro da Instrução Pública e Belas Artes espanhol, Francisco Bergamín (1855-1937), em outubro de 1914, na qual pedia informações sobre a educação em Portugal à Junta para Ampliación de Estúdios da Instituición Libré de Enseñanza (ILE). Esta solicitação desencadeou um estudo que ficou a cargo de Alice Pestana del Blanco (1860-1929), então secretária da instituição, com o título La Education en Portugal (Pestana, 1915). Pestana era uma destacada feminista portuguesa que já tinha participado no Congresso Hispano-portuguêsamericano de Pedagogia11 de 1892 (Leonardo et al., 2009b; Machado, 1896b), apresentando uma comunicação intitulada $O$ que deve ser a instrução secundária da mulher? Foi aí que conheceu o pedagogo espanhol Francisco Giner de los Rios (1839-1915), amigo pessoal de Bernardino Machado. Quando, em 1898, Pedro Blanco Suarez, professor na ILE, escreveu a Bernardino Machado, na altura professor da Faculdade de Filosofia da UC, revelando o seu interesse pela questão feminista em Portugal, este último indicou-lhe o nome dela. Em 1901, Suarez e Pestana casaram-se, tendo Machado por testemunha. Após o matrimónio, esta rumou a Espanha onde ingressou, também, como professora da ILE (Martinez, 1996, p. 101). 
Apesar da proximidade geográfica entre os dois países, o intercâmbio educativo entre Portugal e Espanha foi escasso durante todo o século XIX. Nos artigos d'O Instituto não surgiram, nessa época, muitas referências ao ensino secundário espanhol. Em 1866, António Santos Viegas (1835-1914), professor de Física na Faculdade de Filosofia da UC e mais tarde presidente do IC, descreveu o funcionamento das escolas secundárias espanholas, designadas por Institutos, no seu primeiro relatório (Viegas, 1867) relativo à viagem científica que efetuou nesse ano a instituições de ensino europeias para estudar o ensino experimental da Física (Leonardo et al., 2009b). Os principais contactos luso-espanhóis foram estabelecidos por professores conotados com o republicanismo, como Bernardino Machado, Adolfo Coelho, Teófilo Braga e Alice Pestana. Esses contactos privilegiaram a ILE, instituição espanhola considerada modelar no que respeita ao estudo e concretização das novas correntes pedagógicas. Inclusivamente, alguns artigos da autoria dos autores referidos foram publicados no Boletín de la Institución Libré de Enseñanza (BILE): Pestana (27 artigos), Coelho (12 artigos) e Machado (8 artigos) (Hernandez Diaz, 1998, p. 304). Machado destacou em 1930, durante o seu exílio em Baiona, França, o interesse da ILE sobre a evolução social e política em Portugal, afirmando:

A Institución Libre de Enseñanza era um centro cordial de estreitamento dos laços de visinhança e d'amizade entre Portugal e Espanha. (...) A Institución converteu-se para mim numa segunda família: creio ter hoje o decanado d'idade dos professores honorários. (...) Ali convivi de perto com as primeiras personalidades da arte, sciência, pedagógia e política d'Espanha, todas cheias de simpatia pelas nossas reivindicações democráticas (Hernandez Diaz, 1998, p. 313).

Após 1910, o interesse espanhol pela instrução pública portuguesa intensificou-se. Na sua análise do estado da educação portuguesa, publicada em livro (Pestana 1915), Pestana referiu a criação do Ministério da Instrução Pública, em 7 de julho de 1913, e descreveu, em pormenor, a nova legislação e o funcionamento das escolas do ensino primário, ensino técnico, ensino agrícola e ensino superior. Dedicou também um capítulo à instrução secundária, onde expôs as principais reformas, elogiando a que foi empreendida por Jaime Moniz e João Franco, com enfoque na legislação em vigor (de 1905). Descreveu exaustivamente o funcionamento dos quatro liceus de Lisboa (Pedro Nunes, Passos Manuel, Camões e Maria Pia) 
elogiando o seu espaço físico, estrutura e organização, e dando grande relevância aos novos métodos pedagógicos de ensino ativo, direto e de trabalho individual dos alunos, aplicados às disciplinas científicas. Estas novas metodologias só eram possíveis graças à qualidade de laboratórios e gabinetes de ciência e materiais com que estavam apetrechados os liceus de Lisboa. Pestana concluiu:

Todo esto parece indicar que el momento actual, de laboriosa transformación, prepara a la generación venidera en Portugal una segunda enseñanza que garantice el fortalecimiento de la raza y su integración en el valor total de la civilización (Pestana, 1914, p. 91).

É, no mínimo, estranho verificar que um estudo semelhante não tenha sido comissionado pelo governo português de então, optando-se antes por criar "comissões de sábios", na maioria dos casos professores do ensino superior com conhecimentos limitados do funcionamento dos liceus nacionais. Já em 1890 Adolfo Coelho tinha apresentado à Sociedade Portuguesa de Geografia um "programa de um inquérito ao estado hodierno físico, moral, intelectual e artístico do povo português, do qual devia ser dado lugar importante à instrução pública" (idem), o qual, todavia, não foi levado a cabo.

Apesar dos vários contactos que republicanos portugueses estabeleceram com a ILE, somos forçados a deduzir que o interesse espanhol pela instrução pública portuguesa, especialmente na década de 1910, foi mais acentuado do que o português pelo ensino espanhol. Uma razão para este facto terá a ver com algum atraso do ensino em Espanha em relação a Portugal desde o início do século XX até ao final da Primeira República portuguesa. Mas a isso acresceu uma certa tendência anti-ibérica revelada por alguns pensadores portugueses da época (Adão, 2003, p. 5). Esta situação derivou também do modo como as relações entre os dois países eram transmitidas aos alunos desde tenra idade, fazendo-se crer aos jovens que existia uma perigosa ambição de Castela em retomar a ideia de um só estado ibérico (Hernandez Diaz, 1998, pp. 295-295). Este medo fundamentava-se na fragilidade do regime republicano português, numa altura em que ele procurava uma legitimação tanto nacional como internacional. 


\section{Rubén Landa e o ensino secundário em Portugal}

Uma das mais completas análises do ensino secundário em Portugal durante a Primeira República foi publicada n'O Instituto pela pena do espanhol Rubén Landa Vaz (1890-1978) (Fernandes, cit. em Nóvoa \& Berrio, 1993, p. 165). Este pedagogo, filho de um espanhol e de uma portuguesa, cedo contactou com os ideais da ILE, tendo lido durante a sua infância o Boletín de la Instituición Libré de Enseñanza (BILE), que era assinado pelo seu pai. Após terminar o ensino secundário, Landa ingressou na ILE em 1906, em Madrid, concluindo os seus estudos em Filosofia e Direito em 1912, e doutorou-se em Direito.

A ILE era uma academia privada de ensino secundário e ensino superior, fundada em 1876 por Francisco Giner ${ }^{12}$ e colegas, onde foram postas em prática ideias reformadoras que o ensino oficial não tolerava (Jiménez-Landi, 1996; Mayoral, 2006, p. 77). No quadro do pensamento pedagógico subjacente à ILE, os alunos não eram meros recetáculos de conhecimento, mas sim, e em primeiro lugar, destinatários de uma formação como pessoas livres, e só depois como instruendos a dotar com conhecimentos de matérias específicas. Para atingir este objetivo, a espontaneidade e a criatividade deviam ser estimuladas nos alunos, a fim de que eles fossem agentes ativos da sua aprendizagem. A educação devia ser integral, desenvolvendo tanto o espírito como o corpo, devia ser neutra e isenta no que respeita a correntes religiosas, filosóficas e políticas, devendo ainda ser unificada, eliminando-se a sua divisão em etapas, e em conjunto para rapazes e raparigas. Apostava-se também na colaboração da família no processo educativo.

Tendo concluído os estudos, Landa ocupou vários cargos de responsabilidade na ILE, como bolseiro, nomeadamente o de auxiliar da secretaria da Junta para Ampliación de Estúdios e Investigaciones Científicas (JAE), criada em 1907 com o objetivo de reformar a Universidade espanhola e promover um sistema de bolseiros enviados ao estrangeiro para se formarem como professores e investigadores. Habitava a Residência de Estudantes, criada em 1910 como um colégio universitário. Para além destes centros, a ILE também proporcionou o surgimento de outras instituições como: o Museu Pedagógico Nacional, fundado em 1882 para formar professores do ensino primário; o Centro de Estudos Históricos, criado por 
decreto real em 1910; o Instituto-Escola, instituído em 1918 como uma escola totalmente concebida com base nos princípios pedagógicos da ILE para crianças desde o infantário até aos 17 anos; e o Instituto Nacional de Ciências Físico-Naturais, que, em 1910, incorporou instituições já existentes como o Museu Nacional de Ciências Naturais, o Museu de Antropologia, o Jardim Botânico Real e o Laboratório de Investigações Biológicas, entre outros (idem, pp. 87-92). A JAE terá influenciado, em Portugal, a fundação de uma instituição similar, apenas concretizada em 1929 com a criação da Junta de Educação Nacional (mais tarde chamada Instituto para a Alta Cultura).

Rubén Landa foi enviado a Portugal, em 1918, com o estatuto de bolseiro. A sua escolha para vir ao nosso país teve por base não só a sua fluência na língua portuguesa, mas também as suas ligações familiares a Portugal (que já havia visitado em várias ocasiões). Resultou também, segundo o próprio, da leitura do livro de Pestana (que foi também sua professora) sobre o ensino em Portugal.

A investigação que Landa realizou em Portugal destinava-se a obter o certificado de proficiência que lhe daria acesso a cadeiras de âmbito restrito. Anexa à sua candidatura, numa pequena nota, Landa resumiu assim a sua viagem:

Duração: de 10 de maio a 29 de julho de 1918;

Estabelecimentos visitados: Liceus de Passos Manuel, Pedro Nunes, Camões, Gil Vicente e Maria Pia, Colégio Militar, Escola Normal Superior, Casa Pia, Faculdade de Letras, Jardim-Escola João de Deus, Escola Pública da Tapada da Ajuda (estes em Lisboa); Liceu de Coimbra, Escola Nacional de Agricultura e Universidade (em Coimbra); Liceu de Évora e Casa Pia (em Évora); Liceu de Santarém e Liceu de Leiria.

Contactos estabelecidos: João de Barros (Chefe da Secretaria Geral do Ministério da Instrução), Fidelmio de Figueiredo (director da Biblioteca Nacional), Queiroz Veloso (director da Escola Normal Superior de Lisboa e chefe da Secção de Ensino Universitário do Ministério), Adolfo Coelho, José Leite de Vasconcelos, e Manuel d'Oliveira Ramos (professores da Faculdade de Letras de Lisboa e da Escola Normal Superior), António Sérgio (professor e publicista), Xavier d'Acunha (antigo director da Biblioteca Municipal), Braga Paixão (secretário do Ministério da Instrução Pública), Mendes dos Remédios (Reitor da UC) e Eugénio de Castro (professor da UC) (idem, pp. 116-117).

Rubén Landa apresentou uma memória à JAE intitulada Estado atual de la segunda enseñanza en Portugal (Landa, 1922). Esta, com algumas reformulações e incluindo dados relativos à nova legislação, que ia até ao 
plano de estudos aprovado em 18 de junho de 1921, foi publicada n'O Instituto a partir de 1927 (Landa, 1927). Em 1925, Landa esteve presente no congresso conjunto das Associações Portuguesa e Espanhola para o Avanço das Ciências, realizado em Coimbra de 14 a 19 de junho, onde apresentou uma conferência sobre o ensino secundário em Portugal, integrada na $6 .^{a}$ secção das ciências históricas, filosóficas e filológicas.

Logo na primeira página do seu artigo, Landa elogiou o ensino secundário português, o qual, segundo ele, apresentava na altura resultados melhores do que o espanhol. Demonstrou, desta forma, a necessidade de melhor conhecer o ensino em Portugal, um país tão próximo na história e na geografia e numa situação tão semelhante à espanhola que exigia, tal como o país vizinho, "su incorporación á la corriente de la cultura europea" (Landa, 1927 , p. 44). Referiu, inclusivamente, que algumas novas instituições espanholas tinham sido inspiradas no exemplo português, como o 'Protetorado del niño delicuente' fundado por Alice Pestana (idem, p. 45).

$O$ atraso da instrução secundária em Espanha foi relatado no discurso do Ministro da Instrução Pública, José de Prado y Palacio, no congresso de Bilbau da 'Associación Española para el Progresso de las Ciencias', proferido em setembro de 1919, onde este referiu o seu caráter marcadamente universitário e clássico. Neste discurso, publicado n'O Instituto, Palacio defendeu, também, o envio de pessoal docente ao estrangeiro, em particular os professores mais jovens, para que estudassem as instituições de ensino secundário (Prado y Palacio, 1919, p. 528), e salientou a importância do ensino científico, opondo-se àqueles que "no entienden que un descubrimiento cientííico puede ejercer los más importantes efectos en sus negócios" (idem, p. 533).

No artigo de Landa, seguiu-se uma descrição da história do ensino secundário em Portugal, desde a fundação do país até 1921, com destaque para a reforma de 1894-95 que, apesar de alguns defeitos pontuais nomeadamente: o "esquecimento" ao nível da formação de professores; a redução da liberdade dos professores, que ficaram sujeitos a um regime com muitos preceitos legais que tinham de cumprir; o predomínio do caráter clássico; a ausência da educação física, do canto e dos trabalhos manuais; e a proibição das associações escolares -, foi considerada muito meritória, tendo a "virtud de rehabilitar la enseñanza oficial que tan desprestigiada estaba ante la opinión pública" (Landa, 1927, p. 83). 
A parte essencial do artigo é a descrição, com algum pormenor, do modo como eram ministradas as aulas e o respetivo funcionamento dos liceus, dando particular ênfase ao Liceu Pedro Nunes, como, de resto, já havia feito Pestana. Refira-se que os Liceus Pedro Nunes e Passos Manuel eram os mais modernos em Portugal, tendo os respetivos edifícios sido inaugurados em $1911^{13}$. Landa dedicou um pequeno texto a cada área do ensino, expondo nele as suas conclusões após ter assistido a várias aulas. Referimos aqui apenas a lecionação da Física e da Química.

Landa confirmou que, no curso geral, o ensino das ciências era essencialmente prático, realizando o professor várias experiências diante dos alunos. De acordo com o programa de 1905 para a disciplina de Ciências Físicas e Naturais, ainda em vigor em $1918^{14}$, o estudo da Física iniciava-se no $3 .^{\circ}$ ano de escolaridade (3. ${ }^{a}$ classe), tendo por objetivo familiarizar o aluno com a observação dos fenómenos físicos e proporcionar conhecimentos acerca do manuseamento de instrumentos e aparelhos usados na economia doméstica e industrial. Nas classes seguintes $\left(4 .^{\circ}\right.$ e $5 .^{\circ}$ anos) a Física tornavase descritiva, incluindo noções teóricas sobre as transformações energéticas, descrevendo-se os factos para se induzirem as leis, mas sem entrar em grandes explicações teóricas a priori baseadas em cálculos e procurando sempre revestir os conteúdos de um caráter experimental e prático. A Química iniciava-se também na 3. ${ }^{a}$ classe com algumas noções elementares, o estudo elementar de gases, do ar e água, e experiências com aparelhos simples, iniciando-se os alunos no manuseamento do material do laboratório, dandose continuidade a estas atividades nos anos seguintes. $\mathrm{Na} 5 .^{a}$ classe introduzia-se a química orgânica.

No curso complementar, o ensino científico era o que tinha "alcanzado una realización más perfecta" (idem, p. 209). Na disciplina de Física, estavam previstas uma revisão geral e síntese dos conteúdos lecionados, com a resolução de problemas teóricos e exercícios práticos. Na Química, introduzia-se no $6 .^{\circ}$ ano a hipótese atómica e a determinação de pesos atómicos e moleculares, surgindo no $7 .^{\circ}$ ano a geometria molecular e a química orgânica. Para além das aulas expositivas, lecionadas sempre com base em objetos ou experiências, os alunos tinham uma hora e meia semanal dedicada aos trabalhos práticos individuais de Física, Química, História Natural e Geografia, oficialmente instituídos em $1914^{15}$. Segundo Landa, os 
alunos demonstravam muito interesse por eles, pedindo, com frequência, autorização para trabalhar nos laboratórios em períodos fora das horas regulamentadas (idem). No Liceu Pedro Nunes existia um laboratório destinado ao ensino da Física, uma sala de eletricidade, um anfiteatro com mesa para experiências (seguindo o modelo alemão) e uma pequena oficina para reparações; para o ensino da química havia laboratórios, um anfiteatro disposto para a realização de experiências e uma sala de fotografia. Todas as instalações estavam adequadas ao trabalho dos alunos e os aparelhos eram simples, permitindo aos alunos entender o seu funcionamento e o seu modo de manipulação. Era estimulado o trabalho em grupo, incitando os alunos a adotar uma postura ativa na sua aprendizagem.

O Liceu Pedro Nunes possuía também uma associação escolar muito ativa, com pequena ou nenhuma intervenção do corpo docente, que tinha uma secção literária e científica dedicada a organizar "lecturas, conferencias, discusiones cientificas y publicationes" (idem, p. 437). No final de cada ano era realizada uma exposição escolar, aberta a toda a comunidade local, onde os alunos exibiam e explicavam aos visitantes e familiares os trabalhos realizados ao longo do ano. Os restantes liceus visitados por Landa apresentavam um funcionamento semelhante, apesar de aparentarem menor dinamismo. Os liceus de província, incluindo os de Coimbra e Porto, eram inferiores aos de Lisboa, nomeadamente devido ao facto de os seus edifícios não estarem adaptados às exigências do trabalho experimental (idem, p. 444). O artigo de Landa termina com um anexo (Tabela 2) elencando os trabalhos práticos do curso complementar nos liceus de Lisboa.

Como já foi referido, Landa examinou também algumas das reformas que ocorreram nos anos seguintes à sua visita, que foram incluídas no artigo publicado n'O Instituto, nomeadamente a reforma de 1919, que se seguiu à de Sidónio Pais e apenas afetou a distribuição das disciplinas no ensino secundário, mantendo as linhas gerais da reforma anterior. As Ciências Físico-Naturais no curso complementar de Letras foram substituídas pela Matemática e no curso geral, a partir da 3. ${ }^{a}$ classe, voltou a existir uma só disciplina de Ciências Físico-Naturais (juntando as Ciências Físico-Químicas e as Ciências Naturais) (idem, pp. 221-222). A 18 de junho de 1921, um novo decreto estabeleceu um novo regulamento da instrução secundária, contendo pequenas alterações no plano de estudos. Landa realçou algumas 
determinações, designadamente os artigos $23 .^{\circ}$ e $24 .^{\circ}$, segundo as quais, no exame de ingresso, fosse exigida uma leitura correta assim como uma boa análise do sentido das palavras e das frases. Até ao termo da I República, em 1926, nada mais se legislou sobre o ensino secundário.

Tabela 2

\begin{tabular}{|c|c|}
\hline \multicolumn{2}{|c|}{$\begin{array}{l}\text { Programa dos trabalhos práticos do curso complementar de Ciências dos liceus de Lisboa } \\
\text { (Landa, 1927, pp. 69-71) }\end{array}$} \\
\hline Física & Quí \\
\hline 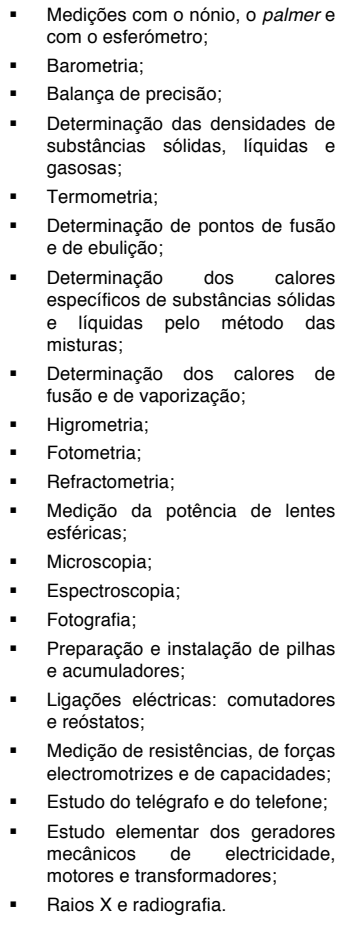 & 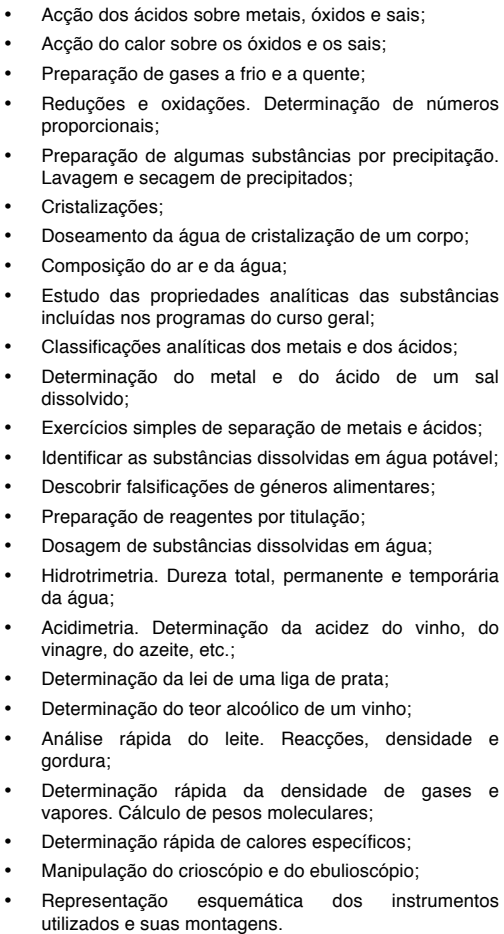 \\
\hline
\end{tabular}

Em 1921, a JAE atribuiu a Landa um novo subsídio para estudar o ensino secundário em França e Inglaterra. Em 1922, Landa enviou um primeiro relatório de França, onde mencionou as discussões então em voga sobre o ensino clássico e o ensino moderno e salientou a importância de uma escola única, acessível a todas as classes sociais. Nunca chegou a elaborar 
qualquer artigo sobre o ensino secundário na Inglaterra. Em 1939, com o fim da guerra civil espanhola (1936-39), exilou-se no México, nunca mais regressando à Península Ibérica.

Apesar de na revista $O$ Instituto não existirem referências ao trabalho de Pestana, o artigo de Landa mereceu o devido destaque, sendo inclusivamente editado em separata. Também Giner publicou um artigo nesta revista e Bernardino Machado dedicou uma memória à Escola Nueva/ILE (Machado, 1896a). Comparativamente, nas revistas espanholas que se dedicavam à educação, publicadas no período estudado, para além da referida BILE, com 53 estudos de autores portugueses, apenas a La Revista Crítica de Historia y Literatura españolas, portuguesas e hispano-americana contém referências aos problemas da instrução pública em Portugal. Nas restantes, este tema encontra-se praticamente ausente (Hernandez Diaz, 1998, pp. 300-304).

A partir de 1928 reduziu-se significativamente o número de artigos dedicados à instrução pública na revista $O$ Instituto. Apesar de não transparecerem quaisquer dados sobre censura prévia, a larga maioria dos professores que ocupavam lugares nos corpos diretivos do IC estavam conotadas com o Estado Novo, pelo que haveria decerto algum cuidado em publicar artigos que contivessem críticas às reformas educativas do novo regime. Assim se poderá explicar que as profundas reformas realizadas a partir de 1926 não tenham merecido qualquer menção nas páginas d'O Instituto. Os tempos eram de forte condicionamento à liberdade de expressão, quer nos jornais académicos, através da seleção dos académicos, quer nos jornais não académicos.

\section{Considerações Finais}

A revolução republicana, embora não tenha produzido alterações, no imediato, na instrução secundária, teve uma enorme repercussão no ensino em Portugal, com a instituição das Escolas Normais Superiores de Lisboa e Coimbra, em 1911, para a formação da classe docente. Passaram a coexistir nos liceus nacionais três tipos de professores: os mais antigos, que careciam de formação pedagógica; aqueles que, por sua iniciativa, tinham adquirido formação ao longo dos vários anos de prática; e os que se haviam formado 
numa Escola Normal Superior. Segundo Landa, os segundos seriam, na altura, os melhores, em resultado da falta de experiência demonstrada pelos últimos (Landa, 1927, p. 203).

A demora em intervir no ensino secundário não será alheia à qualidade atingida com as reformas de Jaime Moniz de 1884/85 e com a reforma de 1905. Destarte, os programas de 1905 mantiveram-se até 1918 (Programas dos Liceus, 1914). É, no entanto, essencial enfatizar a introdução dos trabalhos práticos individuais no curso complementar, uma medida pedagogicamente revolucionária e que cumpria os objetivos de um ensino livre e ativo.

No que respeita à Física e Química, o seu ensino no regime republicano (desde 1905) foi marcadamente experimental e de caráter utilitário, repudiando-se a instrução "memorista" e "livresca" (Valente, 1973, p. 83). Esta asserção é facilmente corroborada pela análise do programa de trabalhos práticos do curso complementar, no qual, para além de atividades experimentais para consolidar aspetos teóricos tratados nas aulas, surgem outros em que se privilegia a aquisição de competências, pelos alunos, para realizarem atividades no quotidiano tais como ligar fios elétricos, telefonar, telegrafar, usar geradores e motores elétricos, detetar falsificações em géneros alimentares, determinar o teor alcoólico do vinho, etc.

Não será difícil concordar com o elogio de Landa, que considerou muito bom o ensino científico no curso complementar de 1918, onde era estimulada a iniciativa individual dos alunos e a sua participação ativa na aprendizagem através da realização, de forma autónoma, de trabalhos práticos e a sua apresentação ao público numa exposição final. Convém, porém, acentuar que o número de alunos de então era extremamente reduzido, medido em percentagem da população juvenil, estando quase limitado a jovens provenientes das famílias mais abastadas, uma classe social reduzida. Em 1920 estavam matriculados nos liceus portugueses 10.159 estudantes (7697 alunos e 2462 alunas) - o que correspondia a menos de 4\% da população escolar ${ }^{16}$-, um número que, apesar de diminuto face aos padrões europeus da época, se pode considerar resultado de uma evolução positiva, pois em 1900 havia apenas 2868 alunos (Valente 1973, p. 101). O ensino secundário português, neste período, poderia, nalguns estabelecimentos mais avançados, ser moderno do ponto de vista 
pedagógico, mas era para muito poucos. Havia ainda grande espaço para desenvolvimentos futuros, que infelizmente foram mais lentos do que seria de desejar.

\section{Agradecimentos}

O primeiro autor agradece à Fundação para a Ciência e Tecnologia a concessão de uma bolsa de doutoramento.

\section{Notas}

1 Esta revista está acessível na íntegra em http://www.uc.pt/bguc/BibliotecaGeral/ InstitutoCoimbra/EdDigital/

2 Uma lista dos artigos publicados n'O Instituto que incidem sobre o ensino e a educação vem reproduzida no Repertório Analítico (séculos XIX-XX) (Nóvoa, 1993, pp. 530-533).

3 Francisco Teixeira Bastos (1857-1902), jornalista e redator do jornal O Século, publicou n'O Instituto uma memória, em 1892, apresentada no Congresso Pedagógico Hispano-português-americano, onde relatava a evolução da pedagogia em Portugal, rematando com a necessidade de uma remodelação do sistema educativo português "fundando-se na hierarchia theorica resultante da syntese positiva e inspirando-se nos princípios mais sãos da pedagogia moderna" (Bastos, 1892, p. 513).

4 A dita comissão incluiu Basílio Telles, Júlio de Matos, José Pereira Sampaio, António Augusto Gonçalves, Joaquim Teixeira Martins de Carvalho, João de Barros, João de Menezes, Caetano Pinto e José de Magalhães.

5 A título de exemplo, no diário de inspiração republicana $O$ Século foi declarado o apoio ao novo diploma, referindo-se que este era uma "reparação" da reforma de 1895 (Brás \& Gonçalves, 2009, p. 103), tendo em 1907 republicanos como Consiglieri Pedroso, diretor do Curso Superior de Letras, e Borges Grainha, professor liceal, aceitado integrar a comissão de exame dos compêndios do ensino secundário, presidida pelo lente de Física, Santos Viegas (idem, pp. 114-115).

6 A discussão entre os que defendiam um ensino mais clássico, com primazia do Latim e do Grego, e os que defendiam um ensino mais moderno, com a prioridade às línguas vivas, foi desenvolvida num extenso trabalho da autoria de Jorge da Rocha Peixoto publicado n'O Instituto (Peixoto, 1910). O autor apresentou as argumentações dos dois lados, mostrando-se favorável ao ensino das línguas vivas.

7 Esta comissão era constituída por doze elementos (cinco professores universitários e sete professores liceais). 
8 De acordo com um primeiro relatório publicado no Diário do Governo de 2 de julho de 1913 (p. 2005).

9 O próprio Adolfo Coelho exerceu funções docentes na Escola Normal Superior de Lisboa.

10 Como forma de estimular a autonomia, o Art. $^{\circ} 8$ determinava que os laboratórios e gabinetes dos liceus deveriam conservar-se abertos aos alunos inscritos nos dias de semana e pelo máximo de tempo possível.

11 Neste congresso realizado em Madrid, em 1892, houve uma representação portuguesa, liderada por Bernardino Machado, que incluiu numerosas personalidades académicas interessadas no tema, onde apresentaram comunicações, algumas das quais foram publicadas n'O Instituto. Contudo, e segundo as palavras de Adolfo Coelho, "apesar do rumor feito em roda dele, não chegou a ser tomado a sério por nenhum estudioso entendido na matéria, indo juntar-se com três outros congressos anteriores do mesmo género à multidão vária e enorme das cosas de España" (Coelho, 1911, p. 73).

12 Este filósofo e pedagogo espanhol destacou-se na introdução do krausismo em Espanha, uma doutrina filosófica que defendia a tolerância académica e a liberdade do ensino, em oposição ao dogmatismo.

13 O Liceu Passos Manuel foi criado em Lisboa em 1837, mas o novo edifício só foi concluído após a implantação da República, acolhendo a primeira aula em 9 de janeiro de 1911. O Liceu Pedro Nunes foi criado logo após a reforma de 1905, pelo Decreto-Lei de 4 de janeiro de 1906; no entanto, o moderno edifício só foi inaugurado a 17 de novembro de 1911, devidamente preparado para o ensino de ciências (Nóvoa \& Santa-Clara, 2003, pp. 507-557).

14 A manutenção dos programas de 1905 tinha sido, oficialmente, estabelecida de acordo com a portaria de 20 de setembro de 1914, aprovada pouco antes da introdução dos trabalhos práticos. Seriam republicados com o subtítulo Instruções para o Ensino em Classe nos Liceus (Programas dos Liceus, 1914).

15 Estes trabalhos individuais educativos já eram realizados antes de 1914 no Liceu Pedro Nunes e estavam autorizados nos liceus que possuíssem material didático suficiente e instalações adequadas. Já em 24 de maio desse mesmo ano, um decreto da autoria de Sobral Cid e Bernardino Machado havia dotado os liceus de maior autonomia, passando a caber ao Reitor, em colaboração com os diretores de classe e o conselho escolar, a direção pedagógica das escolas (Valente, 1973, p. 80).

16 Refira-se que, em 1920 , apenas $27,3 \%$ da população masculina em idade escolar frequentava a escola primária, sendo o número inferior a $20 \%$ para a população feminina (Valente, 1973, pp. 113-114).

\section{Referências}

Adão, A. (2003). Representações de Espanha nos estudos portugueses sobre educação e ensino, produzidos de finais de Oitocentos aos anos 30 do século XX. Revista de pensamento do Eixo Atlântico, 4, 36-47. 
188 António José F. Leonardo, Décio R. Martins \& Carlos Fiolhais

Bastos, T. (1892). Ideias gerais sobre a evolução da pedagogia em Portugal. O Instituto, 40, 489-513.

Brás, J. V., \& Gonçalves, M. N. (2009). Os saberes e poderes da reforma de 1905. Revista Lusófona de Educação, 13, 101-121.

Carvalho, R. (1986). História do ensino em Portugal, desde a fundação da nacionalidade até ao fim do regime de Salazar-Caetano. Lisboa: Fundação Calouste Gulbenkian.

Catroga, F. (2000). O republicanismo em Portugal, da formação ao 5 de Outubro de 2010. Notícias Editorial (2. ${ }^{\mathrm{a}}$ ed.).

Coelho, A. (1911). Questões pedagógicas. O plano geral do ensino público. O Instituto, 58, 71-78, 129-137, 193-202, 257-268, 385-395, 577-587, 641-647, 705-711.

Coelho, A. (1913). Programas e planos de ensino. O Instituto, 60, 401-411.

Fernandes, R. (1973). As ideias pedagógicas de F. Adolfo Coelho. Instituto Gulbenkian de Ciência.

Fernandes, R. (1978). O pensamento pedagógico em Portugal. Biblioteca Breve, vol. 20. Instituto de Cultura Portuguesa.

Fernandes, R. (1979). A pedagogia portuguesa contemporânea. Biblioteca Breve, vol. 37. Instituto de Cultura Portuguesa.

Fernandes, R. (1985). Bernardino Machado e os problemas da instrução pública. Biblioteca do Educador Profissional, 92. Livros Horizonte.

Hernández Díaz, J. M. (1998). La recepción de la pedagogía portuguesa en España (1875-1931). Historia de la educación: Revista interuniversitaria, 17, 289-317.

Jiménez-Landi, A. (1996). La Institución Libré de Enseñanza y su ambiente. Ministerio de Educación y Cultura.

Landa, R. (1922). Estado actual de la segunda enseñanza en Portugal. Boletín de la Institución Libré de Enseñanza, XLVI, 237-246.

Landa, R. (1927). La enseñanza secundaria en Portugal. O Instituto, 74, 44-85, 204225; 75, 202-217, 437-454; 75, 63-75.

Leonardo, A. J., Martins, D. R., \& Fiolhais, C. (2009a). O Instituto de Coimbra: Breve história de uma academia científica, literária e artística. In A. E. Maia Amaral (Coord.), Tesouros da Biblioteca Geral da Universidade de Coimbra (pp. 115125). Coimbra: Imprensa da Universidade.

Leonardo, A. J., Martins, D. R., \& Fiolhais, C. (2009b). O Instituto de Coimbra e o ensino secundário de 1836 a 1910. Revista Portuguesa de Pedagogia, 43(2), 239-260.

Leonardo, A. J. F., Martins, D. R., \& Fiolhais, C. (2011). Bernardino Machado e o ensino experimental das ciências. Revista Portuguesa de Pedagogia, edição-extra.

Lobo, F. M. C. (1919). Reforma da instrução secundária. O Instituto, 66, 179-198.

Machado, B. (1896a). A educação nova em Hespanha. O Instituto, 43, 494-497.

Machado, B. (1896b). Congresso pedagógico hispano-português-americano e exposição pedagógica portuguesa em Madrid. O Instituto, 43, 498-505.

Machado, B. (1900). Curso de pedagogia. O Instituto, 47, 80-84, 130-148, 193-197. 
Mayoral, M. M. R. (2006). Rubén Landa Vaz. Un pedagogo extremeño de la Institución Libré de Enseñanza en México. Editora Regional de Extremadura.

Nóvoa, A. (Dir.). (1993). A imprensa de educação e ensino. Repertório analítico (séculos $X I X-X X)$. Lisboa: Instituto de Inovação Educacional.

Nóvoa, A., \& Berrio, J. R. (Eds.). (1993). A história da educação em Espanha e Portugal - Investigações e actividades. Lisboa: Sociedade Portuguesa de Ciências da Educação.

Nóvoa, A., \& Santa-Clara, A. T. (Coord.). (2003). Liceus de Portugal. Histórias, arquivos e memórias. Edições Asa.

Pestana, A. (1915). La educación en Portugal. Junta para Ampliación de Estudios e Investigaciones Científicas. Imprensa Clásica Española. Cardenal Cisneros, lo, Madrid.

Prado y Palacio, J. (1919). Reforma da instrução pública em Espanha: Discurso proferido na sessão de encerramento do Congresso de Bilbao da Associación Española para el Progresso de las Ciências. O Instituto, 66, 517-536.

Proença, M. C. (2002). A república e a educação. A crise do sistema liberal e a implantação da república. Actas do seminário realizado na Biblioteca Municipal Bento Jesus Caraça (pp. 37-64). Moita: Câmara Municipal da Moita.

Programas dos Liceus (1914). Instruções para o ensino em classe nos liceus - Decreto de 3 de Novembro de 1905, Portaria N. ${ }^{\circ} 230$, Diário do Governo, 20 de Setembro de 1914.

Saraiva, J. A. L. (1993). Academismo, ideologia e história - O Instituto de Coimbra (1910-1945). Coimbra: Faculdade de Letras da Universidade de Coimbra

Valente, V. P. (1973). O Estado Liberal e o ensino: Os liceus portugueses: 1834-1930. Lisboa: Gabinete de Investigações Sociais.

Viegas, A. S. (1867). Viagem scientifica do Dr. António dos Santos Viegas (primeiro relatório - Dezembro de 1866 a Maio de 1867). Diário do Governo, 10 de Outubro de 1867. 
THE INSTITUTE OF COIMBRA AND SECONDARY EDUCATION IN PORTUGAL DURING THE FIRST REPUBLIC. THE PARTICULAR CASE OF PHYSICS AND CHEMISTRY

\section{Abstract}

We analyze the secondary education in Portugal since the reform of 1905 and during the First Republic based on the journal $O$ Instituto, published by the scientific and literary society Institute of Coimbra (IC), with emphasis on the study of Physics and Chemistry. We discuss some articles of IC members, such as Bernardino Machado, Adolfo Coelho and Costa Lobo, who played active roles in some of the reforms implemented. We highlight the relations between Portugal and Spain, in particular the article by Rubén Landa, a Spanish teacher, commissioned in 1918 to study the secondary education in Portugal. His visit was the result of another study, requested by the Spanish government, on the Portuguese public education, conducted in 1914 by the Portuguese Alice Pestana, a teacher in the Instituición Libré de Enseñanza (ILE) in Madrid. The two studies praised the Portuguese secondary education. However, very few pupils attended these schools.

Keywords

Secondary education; Institute of Coimbra; ILE; First Republic

\section{EL INSTITUTO DE COIMBRA Y LA EDUCACIÓN SECUNDARIA EN PORTUGAL DURANTE LA PRIMERA REPÚBLICA. EL CASO PARTICULAR DE CIENCIAS FÍSICAS Y QUÍMICAS}

\section{Resumen}

Se analiza la reforma de la educación secundaria en Portugal después de 1905 y durante la Primera República sobre la base de la revista $O$ Instituto, publicada por la sociedad literaria y científica Instituto de Coimbra (IC), con énfasis en el estudio de la Física y Química. Se discuten algunos de los textos 
de miembros de IC, como Bernardino Machado, Adolfo Coelho y Costa Lobo, que participaron en las reformas emprendidas. Hacemos hincapié en las relaciones entre Portugal y España en el ámbito de la educación, en particular el artículo de Rubén Landa, profesor español que fue comisionado en 1918 para estudiar la educación secundaria en Portugal. Esta visita se produjo como resultado de un estudio solicitado por el gobierno español en la educación pública portuguesa, establecida en 1914 por la portuguesa Alice Pestana, profesora de la Instituición Libré de Enseñanza (ILE), en Madrid. En ambos estudios se elogió el sistema educativo portugués. Sin embargo, esta enseñanza era sólo para un pequeño número de estudiantes.

Palabras-clave

Educación secundaria; Instituto de Coimbra; ILE; Primera República

Recebido em Outubro/2010 Aceite para publicação em Abril/2012 